\title{
DISAGREEMENT ABOUT TASTE AS DISAGREEMENT ABOUT THE DISCOURSE: PROBLEMS AND LIMITATIONS ${ }^{1}$
}

\begin{abstract}
In the present paper I present the metalinguistic solutions to the 'lost disagreement' problem proposed (independently) Sundell and Plunkett [2013] and Barker [2012]. I argue that metalinguistic negotiations about taste, even though successful in explaining the intuition of disagreement in a vast number of cases, are not an accurate solution to the disagreement problem in contextualism when it comes to the most paradigmatic case of "tasty". I also argue against the account of faultless disagreement explained via vagueness of taste predicates [Barker, 2012]. I believe that the notion of faultlessness employed in the discussion of vagueness [Wright, 1994] is a different notion than the one employed in the discussion of taste discourse [Kölbel, 2003].

Keywords: faultless disagreement, lost disagreement, contextualism, predicates of personal taste, metalinguistic negotiations, vagueness.
\end{abstract}

\section{Introduction}

The problem of disagreement has gained a lot of attention in discussions about context-sensitivity and relative truth. At least since the 2003 article by Max Kölbel, disagreement, and in particular - disagreement about taste, has become one of the central problems for various contextual theories. In the present paper, I outline the problem of lost disagreement as an important issue for contextualism. Then I briefly sketch the relativist solution [Lasersohn, MacFarlane] and dismiss it as unsatisfactory. Further, I show alternative options to account for genuine disagreements about taste which are compatible with contextualism. Firstly, I discuss the idea of metalinguistic negotiations proposed by Timothy Sundell and David Plunkett [2013] and provide my critical response to it - in particular, I claim that this strategy does not provide a way of accounting for faultlessness of disagreement. Then 
I turn to a solution along similar lines - the view proposed by Chris Barker that faultless disagreements about taste can be accounted for in terms of vagueness of taste predicates. Finally, I argue that even though the metalinguistic strategies provide a valuable insight into the ways the appearance of disagreement is produced, they are not entirely successful when it comes to accounting for faultless disagreement in the matters of taste.

\section{Lost disagreement}

Disagreements about taste were supposed to be another nail in the contextualist coffin. Let's take the following conversation:

(1) Alice: "This cake is delicious"

Bob: "No, this cake is not delicious"

It seems that to line up with ordinary intuitions, an adequate semantic theory should predict that Alice and Bob are disagreeing. Even more, it should predict that they are disagreeing about something, namely whether a particular piece of cake is delicious. At the same time, it seems, if both speakers are being serious and sincere, we should grant them that they both said something to accuracy of which they were entitled. Neither of them made a mistake saying what he or she said. In some sense, they both said something true. The intuition that in certain cases, speakers can disagree without either of them being wrong about the matter of this disagreement is labeled "faultless disagreement" [Kölbel, 2003].

There are theories which treat such expressions as "delicious" as context-sensitive, which means that the content of such an expression varies from context to context while the character stays constant. In this framework, it is very likely that "delicious" uttered by me would mean something else than "delicious" uttered by you. There are also invariantist accounts of taste predicates which postulate hidden indexicals. According to those views, the content of "delicious" remains constant across contexts but the expression denotes a binary relation "delicious for" and each utterance of it contains a hidden indexical expression referring to the relevant person, standard, or group of people for whom the cake is supposed to be delicious. These differences notwithstanding, both these kinds of views entail that the content of Bob's utterance is not equivalent to the content of Alice's utterance preceded by negation.

If it is not the case that one speaker expresses content $p$ and the other denies it, why are we inclined to think that they are having a disagreement? 
According to Lasersohn [2005], in order for two people to disagree, the contents they express need to be in contradiction. He writes:

To really disagree with [someone], [the speaker] would have to negate a sentence that expresses the same content as his utterance, not the one that expresses the same character (...) (p. 647)

To disagree in this desired, contradicting sense, if Alice says: "This cake is tasty" meaning "This cake is tasty to me", Bob would have to say: "No, it's not tasty" meaning, "It's not tasty to you".

It seems that people do not often inform others what they find tasty ${ }^{2}$, so it is likely that Bob does not mean that. So how come they are disagreeing if there is not one thing that they are disagreeing about? It has been argued that this is the inescapable question that contextualists of all kinds have no conceptual tools to answer [Kölbel, Lasersohn, MacFarlane]. The suggested diagnosis has been that in the contextualist picture Alice and Bob mean different things by calling something delicious and therefore instead of truly disagreeing, they are merely talking past each other. Some contextualists are prepared to bite the bullet [Stojanovic, 2007] and say that sometimes, the speakers take themselves to be disagreeing even though they are involved in a misunderstanding. The question remains, however, how come certain discussions about taste are pertinent and seem to be substantial enough to survive a paraphrase. An interesting answer has been provided by the proponents of the metalinguistic strategy which I describe in section 4 .

\section{Relativism about taste}

Before unveiling the mechanism of metalinguistic negotiation as proposed by David Plunkett and Timothy Sundell, let me first briefly present the other, non-contextualist account designed to explain the odd behavior of predicates of taste. The view which has lately gained a lot of attention is a species of truth relativism discussed, among others, by Peter Lasersohn and almost simultaneously by Max Kölbel ${ }^{3}$. Later, it was developed into a full-fledged theory tackling not only predicates of personal taste, but also other evaluative terms, epistemic modals and so on [MacFarlane, 2014].

Lasersohn proposes that the sentence: " $\mathrm{x}$ is tasty" uttered by two different people will have the same contents across contexts. It is possible, however, for the sentence to be true for one speaker (judge) and false for the other. This way, Lasersohn argues, there is a complete proposition two people disagree about in virtue of its being true to one of them and false to 
the other. MacFarlane has a similar idea. According to relativism, content expressed in judgments about taste is truth-conditionally incomplete. The truth value of this content needs to be relativized to the assessor (or to a parameter of taste, whatever it may be, which is part of the context of evaluation). In this picture, we need context twice: firstly to fix the content (context of utterance) and secondly to evaluate the truth value (context of evaluation $)^{4}$. Application of a solution along these lines, Lasersohn and Kölbel claim, makes place for a consistent and intuitive notion of faultless disagreement - a genuine disagreement among contents in which taste judgments can be uttered felicitously and truly.

The relativist solution is problematic, however. Without going into much detail, one can ask how we can make sense of a notion of disagreement in the situation in which two competent speakers should understand that they are involved in different contexts of evaluation. Clearly, if I utter a taste judgment knowing that taking me as a judge makes it come out true, I should understand that taking someone else as a judge can render it false. Perhaps, if I learnt about it, I would not take myself to disagree with the other person. If we take the relativistic framework to be accurate, we should take the difference in truth conditions to correspond to the difference in subject matter, not the fact that we are assessing the same content differently [Moltmann, 2010]. Some philosophers [Stojanovic, 2007] consider contextualism and relativism to be merely notational variants of each other when it comes to the problem of disagreement. Stojanovic says that ultimately, the decision which one to choose is therefore a matter of taste.

\section{How can speakers disagree if they mean different things by the words they use?}

The problem with taste predicates notwithstanding, it seems that the rumors about the defeat of contextualism are exaggerated. The argument from lost disagreement does not have to be the contextualist's nemesis. Recently, an interesting analysis of disagreement involving evaluative expressions has been proposed by Timothy Sundell and David Plunkett in their article: "Disagreement and Semantics of Normative and Evaluative Terms" [2013]. The authors argue against a popular argument often invoked in metaethical discussions which goes along the following lines:

(2) Alice: "Eating meat is good"

Bob: "No, eating meat is not good" 
Since Alice and Bob clearly disagree, they must mean the same by the word "good". Sundell and Plunkett argue that this kind of reasoning from the assumption that there is genuine disagreement to the conclusion about the meaning of words, is unsound. They argue that even though the disagreement between Alice and Bob is genuine and as persistent as it can get, this does not guarantee that they mean the same by the word "good". To the contrary, the difference in meaning is sometimes exactly what is responsible for the disagreement in a given case ${ }^{5}$. Oftentimes, when speakers are involved in conversations like the one above, they are tacitly negotiating how to best use certain words. They are using words metalinguistically and by using (not mentioning) them, they are communicating information about the appropriate usage in the context in question. This kind of verbal exchange they call 'metalinguistic negotiation'. Many disputes involving normative or evaluative terms (including predicates of personal taste) are not disagreements concerning some shared content (which would result in contextualism being stuck with the lost disagreement predicament), but disagreements between speakers metalinguistically advocating for the appropriate use of a certain expression. Let me present two examples of disagreements which, according to Sundell and Plunkett, are genuine disagreements which are not disagreements about content. The first one is aimed at just showing the general mechanism and the other is an example of a metalinguistic negotiation involving a taste predicate. Each example will be followed by my critical comments.

\section{1.}

To make the difference between various kinds of disagreements clearer, Sundell and Plunkett distinguish two general species thereof: canonical disputes, which are those in which two speakers indeed literally express contradictory contents, and non-canonical disputes, in which the disagreement happens on a non-literal level - it is a contradiction between information communicated via different mechanisms. Among the examples of non-canonical disputes, the authors give the following:

(3) A: "There is one proton in the nucleus of the helium atom"

B: "No, there are two protons in the nucleus of the helium atom"

The propositions expressed in these utterances are not contradictory - in fact they are both true, since their linguistically encoded content is that there are at least $x$ protons. Therefore, the disagreement between $\mathrm{A}$ and $\mathrm{B}$ should not be accounted for in terms of the literally expressed content. What $\mathrm{A}$ and $\mathrm{B}$ disagree about is the exact number of protons in the nu- 


\section{Natalia Karczewska}

cleus of the helium atom and the 'exact' part is communicated by pragmatic means (be it via a scalar implicature or otherwise). This example is aimed at illustrating that genuine disagreement can happen on the pragmatic level of utterances ${ }^{6}$. According to the authors, it also shows that it is not the case that if two people disagree, at least one of them must be saying something false.

\section{Comment}

It seems to me that this last diagnosis is aimed at promising a little more than can be delivered - namely, an account of blamelessness of the speakers showing in stressing the fact that none of them said something false. Certainly, we do participate in many disputes in virtue of expressing some contents pragmatically. However, the notion of saying, which involves Gricean what is said is highly theoretical. Sundell and Plunkett say that even though $\mathrm{A}$ and $\mathrm{B}$ are disagreeing, it is not the case that one of them says something false. That is true, but we know now that the disagreement is not happening on the level of what is said. It is happening on the level on what is meant. The content conveyed pragmatically is:

(4) A: "There is exactly one proton in the nucleus of the helium atom"

B: "No, there are exactly two protons in the nucleus of the helium atom"

In (4), A means to communicate a proposition which is false. It seems, therefore, that saying that $\mathrm{A}$ and $\mathrm{B}$ are disagreeing even though neither of them said something false sensu stricto, is a bit of a trick. They are disagreeing because they communicated some contents and, at the same time, one of them was false. A is fully accountable what she communicated.

Another problem is that Sundell and Plunkett, here as well as in other examples used to support their hypothesis, seem to be ignoring speakers' intentions. Most (no matter how) competent language speakers are not familiar with the Gricean story of number words, nor with the mechanism of scalar implicature. I would like to argue that A and B will most often consider what A and B communicate as presented in (4) as the literal content of their utterances and thus they would consider themselves to be involved in a canonical dispute. If it was not the case, B's reaction to A's utterance would be considered somewhat odd.

\section{2.}

The example of metalinguistic negotiations about taste proposed by Sundell and Plunkett is the following:

(5) A: "This chili is spicy"

B: "It's not spicy at all" 
(5) is of special interest to all of us interested in disagreements about taste. According to Sundell and Plunkett, in (5) the speakers are not reporting about the objective degree to which the chili is spicy (they are not saying: "it's spicy $9 / 10$ " and "no, it's spicy only $3 / 10 ")$. Instead they are pragmatically advocating for the threshold from which spiciness should be predicated of the chili in this context. This idea is linked to the generally accepted view of semantics of relative gradable adjectives [Kennedy, 2007].

According to Kennedy, relative gradable adjectives can truthfully refer to objects only when a cutoff point (threshold) is established in a given context. Such adjectives as "tall", "big" or "rich" operate on scales (of height, size, wealth respectively) and mean something only once a comparison class (for a first-grader, for a city, for a philosopher) and a threshold on a scale (say, $120 \mathrm{~cm}, 1$ million people, x dollars/a year) are established. Most of the time speakers assume that these parameters are common to the participants of the conversation and use such adjectives to communicate something about the world. For instance, if I say: "My 6 year old cousin is tall", I mean to inform you that my cousin has (roughly) over $120 \mathrm{~cm}$ of height.

Sometimes, however, I can use the exact same sentence to communicate something about the context and not about the world. Let us imagine that you know very little about six year olds and their heights, but you are at a family reunion, we are looking at my cousin and you ask: "What counts as tall in the first grade?" Now, when I answer: "My cousin is tall", I inform you about the appropriate way of using the word "tall". I have not told you where exactly the cutoff lies on the scale but I have reduced your ignorance in this matter a little bit. This kind of use was called by Chris Barker [2002] "metalinguistic use". (I will say a bit more about this in section 5 of the present paper).

Sundell and Plunkett employ the notion of metalinguistic use to explain such disagreements as the one in (5). According to them, A and B are metalinguistically negotiating the appropriate way of using the predicate "spicy". A communicates: "we should use "spicy' in such a way that it applies to the chili" and B denies it. They are not talking about the state of the world since they "mutually know the facts about the chemical hotness of the chili" (p. 16).

\section{Comment}

Even though this explanation of what is going on in (5) sounds quite appealing, I see two problems with it. In the first place, I see no grounds for the claim that $\mathrm{A}$ and $\mathrm{B}$ mutually now the facts about the chemical hotness of the chili. In fact, I believe that it is quite likely that if they were given 
a one-to-ten scale, they would assign different degrees to the chili instead of giving the same value and arguing about the threshold of spiciness. It seems that the subjective character of the predicates of taste has something to do with the personal experience of the speaker. We simply sometimes experience things differently and it is reflected in our language. This can be incorporated into the semantics of the word by postulating an "experiencer argument" as a part of meaning of a taste predicate [e.g. McNally and Stojanovic, forthcoming]. In my 2015 paper [forthcoming] I propose a slightly different strategy. I postulate a sort of 'personal algorithm' which each speaker uses to determine whether a given taste predicate applies to something - for me a chocolate cake is tasty when it displays a certain degree of moisture, a balance of sweetness and bitterness, when it has a certain consistency and so on. Without going into the details of my proposal, I would like to hint that it is motivated by my conviction that Sundell and Plunkett's idea of disagreeing about taste as negotiating metalinguistically about the applicability of "tasty" has its limits. I believe that we can negotiate to a certain extent and if we do not manage to convince our interlocutor to appreciate certain qualities of some food, then we are stuck in the nonnegotiable zone of purely subjective experience where contextualism faces the lost disagreement problem again.

More importantly, however, I would like to notice that in (5) just as in the example from section 4.1., nothing guarantees that $\mathrm{A}$ and $\mathrm{B}$ have the appropriate communicative intention which is required for a metalinguistic use of a predicate. In the example about the tall first grader, first, I had the intention to let my interlocutor know that my cousin was taller than the shared threshold of height. In the second case, I had a distinctive communicative intention to let my interlocutor know about the proper way to use "tall" in the present context. If A and B have an analogical intention in (5), then I agree, the example is a species of metalinguistic negotiation. Nevertheless, I think that very often, speakers do not have this very intention. It may very well be the case that in (5) A tastes the chili and it burns her tongue. She says, in order to inform B about the state of the world (or her experience), that the chili is spicy. B tastes the chili and does not share A's experience. He says that the chili is spicy with the intention inform her that he excludes what she said from the set of his beliefs about the world (or to say that he does not have the same kind of experience).

We could also imagine that with yet completely different intentions, $\mathrm{A}$ and $\mathrm{B}$ could communicate something completely different in (5). A could be trying to convey her opinion that the chili should not be served to their grandma who has a sensitive taste while B could be arguing otherwise. In 
this case, (5) would be a disagreement between pragmatically communicated contents. This is absolutely plausible and constitutes a satisfactory explanation of the intuition of disagreement. One should remember, however, that this would probably not be a faultless disagreement that we look for in disagreements about taste.

I believe that the appropriate intention, i.e. the intention to say something about the words we are using is vital to classify a given exchange as metalinguistic. Otherwise, this classification will be arbitrary. After all, if the conscious intention did not matter, when $\mathrm{A}$ and $\mathrm{B}$ point to an elephant and say:

(6) A: "This is an elephant"

B: "No, this is not an elephant",

could freely, and in any arbitrary case, be considered a metalinguistic negotiation regarding the appropriate way of using the word "elephant".

To sum up this section, let me remind the reader of my goals. I tried to show that Sundell and Plunkett provide an interesting strategy of accounting for the intuition of disagreement in disputes which are not canonical. I also tried to point out that the metalinguistic strategy does not work well unless we guarantee that the speakers have appropriate intentions. Moreover, I argued that metalinguistic negotiation about taste predicates does not necessarily secure the notion of genuine disagreement and definitely does not secure the notion of faultless disagreement.

No account of faultlessness of a disagreement about taste seems to be a shortcoming of Sundell and Plunkett's strategy. Their idea was to some extent powered by the linguistic machinery provided by Chris Barker [2002, 2012]. His paper "Negotiating Taste" explains faultless disagreements about taste as cases of failure to negotiate vague standards of taste predicates. Since Sundell and Plunkett do not seem to provide any account of faultlessness, let me turn to Barker's view.

\section{Barker's account of faultless disagreement via vagueness of taste predicates}

In his 2012 paper "Negotiating Taste" Chris Barker postulates a connection between vagueness of predicates of taste and faultless disagreement. He applies his framework for modeling the update effect [2002] on the use of vague predicates in general to predicates of taste. The central idea here is that asserting (and accepting) a sentence involving a taste predicate helps to 
eliminate some part of uncertainty about the applicability of this predicate in a context.

The characteristic (and defining) features of vague predicates that will interest us here are the following:

(a) They have borderline cases as well as clear-cut cases: a Polish eighteen year old girl is definitely tall when she is $180 \mathrm{~cm}$ tall and definitely not tall when she is $150 \mathrm{~cm}$ tall. If she is $170 \mathrm{~cm}$ tall, we are not sure what to say - that would be a case of borderline tallness.

(b) They are prone to Sorites Paradox: a Polish eighteen year old girl is tall when she is $180 \mathrm{~cm}$ tall. Any such girl is also tall when she is $1 \mathrm{~mm}$ shorter than a tall one. (...) Therefore, any Polish girl who is $140 \mathrm{~cm}$ tall is also tall.

Barker distinguishes the descriptive use of a vague predicate from the metalinguistic use. This distinction has been made in part 4.2. with the tall first grader example. Using the sentence: "My 6 year old cousin is tall" in order to inform my interlocutor about the height of my cousin would be a descriptive use, provided we mutually know the approximate standard of height. However, uttering the same phrase to inform her what counts as tall in a given comparison group would be a metalinguistic use. The information I convey in the latter utterance is, in particular, that the threshold for "tall" cannot be set higher than the value exemplified by my cousin. In other words, the conversation can reduce uncertainty about the vague standards. In this case, saying that $\mathrm{x}$ is tall, updates the context to the effect that we know that all things taller or equal $\mathrm{x}$ are also tall.

Just like in the Sundell and Plunkett's picture, speakers can be in disagreement in virtue of metalinguistically communicating contradictory content.

Moreover, speakers can, according to Barker, faultlessly disagree about the applicability of a vague predicate ${ }^{7}$. After Crispin Wright, he writes:

(...) a statement's possessing (one kind of) vagueness just consists in the fact that, under certain circumstances, cognitively lucid, fully informed and properly functioning subjects may faultlessly differ about it. [Barker 2002, p. 421]

When we are talking about a borderline case and I decide to call a given person tall while you decide against it, then according to Wright (and Barker), neither of us made a mistake. In fact,

(...) since no individual has privileged access to or authority over linguistic convention, there is no recourse for disputes over vague standards. It is this lack of authority that accounts for the impression of faultlessness. [Barker 2012, p. 242] 
It could be the case, however, that what determines the standard of tallness is the prevailing pattern of use of the predicate "tall" in a linguistic community. However, according to Barker, no individual speaker has the authority to judge what this pattern is.

So, faultless disagreement happens when the speakers agree about the relevant fact about the world but have different assumptions about the cutoffs of a given vague predicate. All gradable predicates are vague and predicates of personal taste are gradable. Therefore, Barker argues, faultless disagreements about taste can be explained in terms of their vague character. This means that in his framework (1):

Alice: "This cake is delicious"

Bob: "No, this cake is not delicious";

can be a faultless disagreement. The dynamic view predicts that it would not be faultless if previously, in the course of the discourse, B had said that something else was delicious and that the cake was more delicious than that other thing. Otherwise, since Alice and Bob are disagreeing not about the state of the world but about the cutoff of applicability of "delicious", the disagreement is faultless.

Barker concedes that it is not the case that all disagreements about taste which are also about the discourse are like that. He says that perhaps, sometimes speakers disagree about the exact degree of tastiness the food has. He also agrees with Sundell [2011] that some taste judgments are about the norms (though not necessarily aesthetic ones).

\section{Criticism of Barker's project}

I would like to argue that the notion of faultlessness of disagreement argued for by Wright and Barker - that is the one concentrating on the vagueness of predicates - is a notion that captures a different phenomenon than the one postulated by the proponents of relativist strategies, e.g. Lasersohn and MacFarlane. The faultlessness of the former kind has to do with the lack of authority when it comes to deciding about the applicability of the predicate in contentious cases. The speakers are not being held responsible for the judgments they make because the imprecision of their language makes each utterance justified when it comes to the borderline cases. The latter kind of faultlessness which is the one postulated in the case of discussions about taste does not have much to do with the shortcomings of the language. It is supposed to capture the subjective character of taste judg- 
ments. This subjectivity has to do with the intuition that it is very difficult to argue against the truth of somebody's honest utterance of " $\mathrm{x}$ is delicious".

That having been said, I would like to argue that even though taste predicates are vague just as all other gradable adjectives, it is not vagueness that is responsible for the intuition of faultlessness in case of disputes centering on taste. In the first place, it is not clear what borderline cases of "tasty" or "delicious" could be. The same goes for clear-cut cases - it is not the case that there are certain foods that all competent speakers of English would call tasty. Most speakers would probably consider chocolate delicious but when somebody disagrees, we would not just bluntly tell them they are wrong. Most people would also consider rotten food disgusting but a quick internet search would prove wrong those, who think that there are no fans of fermented shark meat (which "has a powerful smell of ammonia smell and a consistency like cheese"), Casu Marzu or Natto ${ }^{8}$.

It is difficult to imagine that when Alice and Bob disagree about the cake being delicious, they are considering a borderline case and therefore, their utterances are faultless. Semantics of taste predicates constitutes a bit of a constraint here. Hans Kamp [1975] and Ewan Klein [1980] postulate a distinction between unidimensional and multidimensional adjectives. The former are the adjectives such as "tall" whose meaning is such that a single criterion is used to order individuals (items) according to the property they refer to. "Tall" operates on a linear scale and therefore we can order things (or people) along this scale according to the value of height they display. Multidimensional adjectives, such as "healthy", on the other hand, do not operate on a simple linear scale. They involve multiple criteria (which in turn perhaps are structurally similar to unidimensional adjectives) to order individuals. We can image that for "healthy" it could be: the cardiac system function, cholesterol level, immunity to diseases and so on. "Tasty" seems to be a multidimensional adjective whose dimensions can be: smell, aroma, texture, the balance of various tastes (salty, sweet, umami etc.), and so on. For this reason it is difficult to have one scale for different kinds of food and to be able to decide whether a meringue cake is tastier than broccoli soup or whether Kopi Luwak coffee is tastier than Hungarian goulash. It is also highly unlikely that Alice and Bob are disagreeing about a piece of cake which happens to be borderline delicious. It might be the case that for one of them it is definitely delicious and for the other it is definitely awful. To postulate that all of our uses of taste predicates concern borderline cases would be ad hoc and definitely question begging. 
This is not to say that we cannot ever be stuck in the borderline zone of tastiness. I can imagine trying to decide whether salty caramel is tasty or trying tomato soup which is almost tasty but maybe to be really tasty requires a pinch of salt. It might happen that I am disagreeing about that with my interlocutor and that in this case it could be a faultless disagreement in the sense provided by Barker. This however, seems to be a very rare kind of situation.

I do not wish to argue, either, that there is no context update effect when somebody uses a taste predicate in a discourse. As the reader remembers, according to Barker, using a vague predicate can make commitments about its use in the further conversation. If I say that a certain tree is tall, my interlocutors would be correct to assume that I should call any tree taller than that tree tall as well. The same goes for "tasty": when I say that yesterday's cake was tasty and that today's cake is tastier, then I'm committed to saying that today's cake is tasty as well. On the other hand, if I say that some particular cake is tasty, they will gain no practical tools to determine whether the next thing they eat that they consider tastier than the previous one, I would deem tasty as well. However, since they have learnt that I considered some particular cake tasty, then provided they have identified what made this cake tasty for me, they might make future predictions about the kinds of cake I will call tasty as well.

One last point has to be made in connection with Barker's view. As Joanna Odrowąż-Sypniewska writes: "Wright thinks of the possibility of there arising a faultless disagreement concerning borderline cases as a characteristic trait of vagueness" [p. 6, forthcoming]. If Wright considers faultless disagreement as something to be used as one of the defining traits of vague predicates, then we should not explain faultless disagreement in the matters of taste via vagueness of taste predicates, as the circularity of this move is quite transparent.

\section{Conclusion}

In this paper I presented the problem of lost disagreement in contextualism and some of its contextualist-friendly solutions. I have tried to show that the metalinguistic negotiation explanation provided by Sundell and Plunkett is not entirely successful in securing genuine disagreement in negotiating "tasty" which has to do with the multidimensional character of the adjective. I was also arguing that metalinguistic use of a predicate of taste requires special intentions on the speakers' part. Finally, I pointed 


\section{Natalia Karczewska}

out that this strategy does not help much to account for faultless disagreements about taste. For this reason, I turned to the dynamic framework of Barker, according to whom faultless disagreement about taste is caused by the failure to negotiate vague standard of the predicate. I argue that the faultlessness that he is postulating is a different species of faultlessness than the one sought by the proponents of faultless disagreement about the matters of taste.

\section{N O T E S}

${ }^{1}$ Financial support for this work was provided by the National Science Centre research project no. 2013/11/N/HS1/04817. I am grateful to Chris Barker, Joanna OdrowążSypniewska and Stephen Schiffer for their insightful comments on the earlier drafts of this paper and to the audiences of PhiLang 2015, New York Language Workshop and the $6^{\text {th }}$ Annual University of Calgary Graduate Philosophy Conference for inspiring discussion.

2 Sometimes, however, it does happen that we take an exocentric perspective [Lasersohn, 2009] when uttering taste judgments. A father would sometimes try to convince a child that the cough syrup is tasty or a dog owner would buy a particular brand of dog food which is supposed to be tasty even though she would never describe it as tasty to her.

3 This kind of relativism has also been called "non-indexical contextualism" [Kölbel, 2003 and MacFarlane, 2007].

4 These two steps do not have to happen one after the other. They can happen simultaneously.

5 The authors do not take into account a simple misunderstanding scenario that could be happening in the "good" case. It could be the case that Alice is using "good" to mean "good for your health" while Bob is using "good" to say "morally good". We assume that in the kind of examples proposed by Sundell and Plunkett here, both speakers are using "good" from the same order, to mean, say, "morally good".

${ }^{6}$ It is not supposed to be evidence against the "disagreement means sameness of meaning" argument.

7 There are many theories of vagueness, some of which do and others do not make place for faultless disagreement. I am focusing here of Wright's framework as it is the one from which Barker's view derives. For a larger discussion of how other vagueness theorists treat disagreement see, e.g. J. Odrowąż-Sypniewska [forthcoming].

8 I will spare the reader descriptions of these delicacies. For the brave and curious ones: http://www.forbes.com/pictures/eeji45hdek/kumis-jpg/

\section{R E F E R E N C E S}

Barker, Ch., (2002), "The Dynamics of Vagueness", Linguistics and Philosophy 25, $1-36$.

Barker, Ch., (2013), "Negotiating Taste", Inquiry: an Interdisciplinary Journal of Philosophy, 56:2-3, 240-257. 
Braun, D., (2015), "Indexicals", Stanford Encyclopedia of Philosophy, http://plato. stanford.edu/entries/indexicals/\#StrConInvHidIndInvUnaCon.

Kamp, H. (1975), "Two theories about adjectives", [In:] E. L. Keenan (Ed.), Formal semantics of natural language, 123-155. Cambridge: Cambridge University Press.

Karczewska, N. (forthcoming in 2016), "Metalinguistic Negotiations as Disagreements about Taste - a Few Critical Remarks", Filozofia Nauki 1/2016.

Kennedy, C. (2007), "Vagueness and Grammar: The Semantics of Relative and Absolute Gradable Adjectives", Linguistics and Philosophy 30 (1), 1-45.

Klein, E. (1980), "A semantics for positive and comparative adjectives", Linguistics and Philosophy 4, 1-45.

Kölbel, M. (2003), "Faultless disagreement", Proceedings of the Aristotelian Society 104: 53-73.

Lasersohn, P., (2005), "Context Dependence, Disagreement and Predicates of Personal Taste", Linguistics and Philosophy 28 (6), 643-686.

Lasersohn, P., (2009), "Relative Truth, Speaker Commitment, and Control of Implicit Arguments", Synthese 166.2, 359-374.

MacFarlane, J. (2009), "Non-indexical contextualism", Synthese 166(2), 231-250.

MacFarlane, J. (2014), "Assessment Sensitivity. Relative Truth and Its Applications", Oxford: Oxford University Press.

McNally L., Stojanovic I. (2015), "Aesthetic adjectives", http://www.upf.edu/pdi/ louise-mcnally/_pdf/publications/McNallyStojanovic.pdf

Moltmann, F., (2010), "Relative Truth and the First Person", Philosophical Studies $150(2), 187-220$.

Odrowąż-Sypniewska, J. (forthcoming), "Faultless disagreement, predicates of personal taste and vagueness"

Plunkett, D., Sundell, T. (2013), "Disagreement and the Semantics of Normative and Evaluative Terms", Philosophers'Imprint, Vol. 13 No. 23, 1-37.

Stojanovic, I. (2007), "Talking about taste: disagreement, implicit arguments and relative truth", Linguistics and Philosophy 30 (6): 691-706.

Sundell, T. (2011), "Disagreements about taste", Philosophical Studies 155: 267288.

Wright, C., (1994), "Truth and Objectivity", Cambridge, MA: Harvard University Press. 